Quebec Cooperative Study of Friedreichs Ataxia

\title{
Cardiac Angiographic Findings in Friedreich's Ataxia
}

R. GUERIN, G. ELIAS, A. DAVIGNON, M. COTE,

G. GEOFFROY, B. LEMIEUX, AND A. BARBEAU

SUMMARY: Angiograms of 12 patients with typical Friedreich's ataxia were analyzed. The results corroborate previous reports and justify the conclusion that the cardiomyopathy is of the hypertrophic type. In 10 of 12 cases, the hypertrophy is concentric, and non obstructive. Less frequently (2 cases), this hypertrophy is accompanied by diffuse hypokinesis and depressed ejection fraction.

RÉSUMÉ: Les angiogrammes de 12 patients souffrant d'ataxic de Friedreich "Iypique" furent analysés. Les résultats de la présente étude corroborent certains rapports antérieurs et justifient la conclusion que cette maladie est probablement hypertrophique. Chez 10 des 12 cas, l'hypertrophie est concentrique et non obstructive. Dans 2 cas, cette hypertrophie est accompagnée par une hypokinésie diffuse et une fraction d'éjection déprimée.

From the Hôpital Ste-Justine, Montreal; the Hôpital Maisonneuve-Rosemont, Montreal; the Centre Hospitalier de I'Université de Sherbrooke; and the Clinical Research Institute of Montreal.

Reprint requests for the complete supplement on Friedreich's ataxia to: Dr. André Barbeau, Clinical Research Institute of Montreal, 110 Pine Avenue West, Montreal, H2W IR7 Quebec, Canada.

\section{INTRODUCTION}

Boyer et al. (1962) were the first to report angiographic findings in patients with Friedreich's ataxia. Commenting on a single diagnostic right ventricular angiogram, they noted a diffuse hypokinesia of the left ventricle. Thoren (1964) reported in one of 2 cases an angiogram showing infundibular stenosis compatible with hypertrophic cardiomyopathy. In a 24 year old patient, Gach et al. (1971) observed an hypertrophic obstructive cardiomyopathy involving both ventricles. Elias et al. (1972) reported a similar case without a right ventricular angiogram.

Ruschhaupt et al. (1972) analyzed five biplane right ventriculograms and five right anterior oblique (RAO) left angiograms. They noted left ventricular hypertrophy in all cases without commenting on its severity. The left ventricular cavity was deformed in two cases and in two cases of idiopathic hypertrophic sub-aortic stenosis (IHSS), the right coronary artery was dilated. They concluded that the diffuse hypertrophic cardiomyopathy in Friedreich's ataxia is comparable to IHSS.

Pernot et al. (1973) also concluded in their study of 13 cases that anatomically the cardiomyopathy is hypertrophic in type and frequently functionally obstructive. Both right and left infundibular hypertrophy may be present.

Finally, Gabriel and collaborators (1974) reported a case with diffuse ventricular and septal hypertrophy without obstruction and with a small left ventricular cavity.

\section{MATERIAL AND METHODS}

Angiograms of 12 patients with classical Friedreich's ataxia were available for study. Right ventriculograms, recorded on $16 \mathrm{~mm}$ or $35 \mathrm{~mm}$. films, were obtained in the biplane, anteroposterior (AP) and lateral projections in 5 and in a single plane (AP) in two. The left ventricular angiograms were recorded in a biplane projection in six cases and single plane (RAO or AP) in six others (Table 1).

\section{RESULTS}

In all cases with available right ventricular angiograms, a variable degree of hypertrophy of the parietal and particularly the septal band was visible in systole with reduction of the infundibular lumen especially in the lateral projection (Table 1, Figures 1 and 2). In 5 cases, the interventricular septum was hypertrophied and protruded into the right ventricular sinus. The pulmonary valves and artery were normal in all cases.

The morphology of the infundibulum appeared comparable to the secondary hypertrophy associated with pulmonary valvular stenosis (Figures 3, 4 and 5). Although infundibular narrowing of varying degree was visible, no significant valvular or subvalvular peak systolic pressure gradient was present at rest or during isoproterenol infusion.

In all cases, the left ventricular angiogram showed a diffuse hypertrophy of varying degree with a normal or reduced end-diastolic cavity, in some approaching a "ballerina foot" or comma shaped mor- 
TABLE 1

HEMODYNAMIC DATA

\begin{tabular}{|c|c|c|c|c|c|c|c|c|c|c|c|c|c|c|c|c|}
\hline \multirow{3}{*}{ 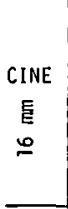 } & \multirow{3}{*}{ 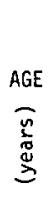 } & \multicolumn{8}{|c|}{ RIGHT VENTRICLE } & \multicolumn{7}{|c|}{ LEFT VENTRICLE (A.P. \& LAT.) } \\
\hline & & \multicolumn{2}{|c|}{ OUTFLOW TRACT } & \multicolumn{2}{|c|}{ A.P. } & \multicolumn{2}{|c|}{ LAT. } & \multirow{2}{*}{\begin{tabular}{|l}
\multicolumn{1}{|c}{ SINUS } \\
$\begin{array}{l}\text { COMPRESS. } \\
\text { BY SEPTUM }\end{array}$
\end{tabular}} & \multirow[t]{2}{*}{ P.A. } & \multirow{2}{*}{\begin{tabular}{|c|} 
SINUS \\
$\begin{array}{c}\text { DIFFUSE HYPERT } \\
\text { + WALL } \\
\text { THICKNESS }\end{array}$ \\
\end{tabular}} & \multicolumn{3}{|c|}{ OUTFLOW TRACT } & \multirow[t]{2}{*}{ MITRAL $V$. } & \multirow{2}{*}{$\begin{array}{l}\text { LEFT } \\
\text { CORON. }\end{array}$} & \multirow{2}{*}{$\begin{array}{l}\text { ASC. AO. } \\
\text { LAT. VIEW }\end{array}$} \\
\hline & & $\begin{array}{l}\text { HYPERTROPHY } \\
\text { P.B.+S.B. }\end{array}$ & $\begin{array}{c}\text { LATERAL } \\
\text { COMPRESSION } \\
\text { BY SEPTUM }\end{array}$ & & $\mathrm{cm}$. & & & & & & \begin{tabular}{|l} 
COMPR.BY \\
SEPTUM \\
LAT. VIEW
\end{tabular} & $\begin{array}{l}\text { DIAM. } \\
\text { SYST. }\end{array}$ & STENOSIS & & & \\
\hline MGG1 & 12 & + & + & 1.6 & 3.6 & 0.8 & 1.8 & - & 2.5 & $+0.8 \mathrm{~cm}$ & + & 2.2 & - & $\begin{array}{l}\text { Mitral insuf. } \\
\text { post. mitr. val. } \\
\text { Bulging. }\end{array}$ & $+\dot{\gamma}$ & 2.4 \\
\hline MGG2 & 13 & + & + & 3.2 & 4.2 & 1.0 & 3.2 & + & $2.5 \|$ & +1.2 & + & 1.8 & - & N. & N. & 2.0 \\
\hline MGG3 & 17 & + & + & 2.4 & 4.4 & 1.4 & 2.2 & + & 2.4 & +1.0 & - & 2.4 & - & $\begin{array}{l}\text { Post Bulging } \\
\text { mit., vaive. }\end{array}$ & N. & 2.4 \\
\hline MGG4 & 19 & + & + & 1.6 & 3.6 & 0.8 & 1.8 & + & 2.2 & +1.3 & - & 2.2 & - & N. & $+\varphi$ & 2.4 \\
\hline MGG5 & 17 & + & + & 2.8 & 3.2 & 0.6 & 1.2 & + & 1.6 & $\begin{array}{l}+\quad 1.3 \\
\text { post. pap } \\
\text { muscle }\end{array}$ & $\cdots$ & 2.0 & - & Small bulging & +7 & 2.6 \\
\hline$\overline{\text { MGG6 }}$ & 16 & & & & & & & & & $+\quad 1.2$ & - & 2.0 & & N. & +1 & 2.0 \\
\hline МАB & 26 & + & A.P. VIEW 0 & $\overline{\mathrm{NLY}}$ & & & & + & & + & OAG. OAD A.P & & & N. & +7 & $\mathrm{~N}$ \\
\hline MAB4 & 22 & + & & & & & & & & + & GAD & & & N. & N. & $N$ \\
\hline MAB23 & 27 & & & & & & & & & $\begin{array}{l}+ \\
\text { tContractility } \\
\text { Left } v \text {. dilat. }\end{array}$ & OAD OAG & & & N & N & $N$ \\
\hline SBL4 & 14 & & & & & & & & & + & $O A D$ & & & $\begin{array}{l}\text { Slight regur- } \\
\text { gitation }\end{array}$ & $+A$ & N \\
\hline SBL3 & 15 & & & & & & & & & $\begin{array}{l}+ \\
\text { tcontract. } \\
\text { L.V. Dilat. }\end{array}$ & FacetAo asc & & & N & N & N \\
\hline SBL.15] & 12 & & & & & & & & & $\begin{array}{l}+ \\
\text { Hypertr asym? } \\
\text { distoted synus }\end{array}$ & DAD & & & N & $\uparrow$ & N \\
\hline
\end{tabular}

Table 1-Summary of findings and dimensions of right and left ventricular angiograms. P.B.= Parietal band; S.B. $=$ Septal band; A.P. $=$ Antero-posterior; LAT $=$ Lateral compress $=$ Compression; P.A.=Pulmonary artery in $\mathrm{cm}$.; Hypert.=

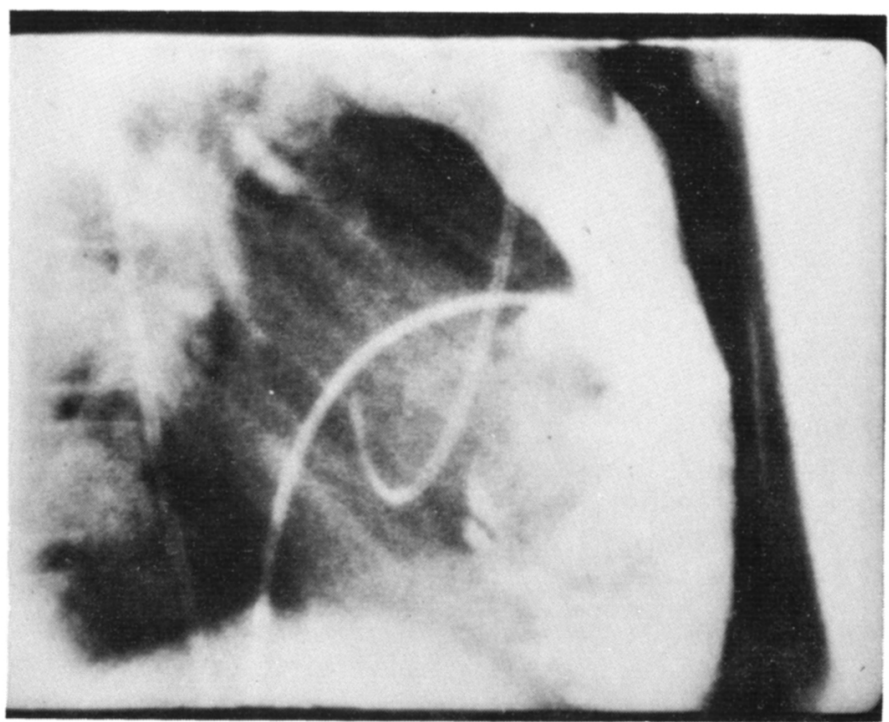

Figure I - Right ventricular angiogram in diastole (lateral projection).
Hypertrophy; L.V. = Left ventricle; Dilat. = Dilatation; $\mathrm{OAG}=$ Left anterior oblique; OAD = Right anterior oblique; Ao. Asc. $=$ Ascending aorta; $\mathrm{N}=$ Normal.

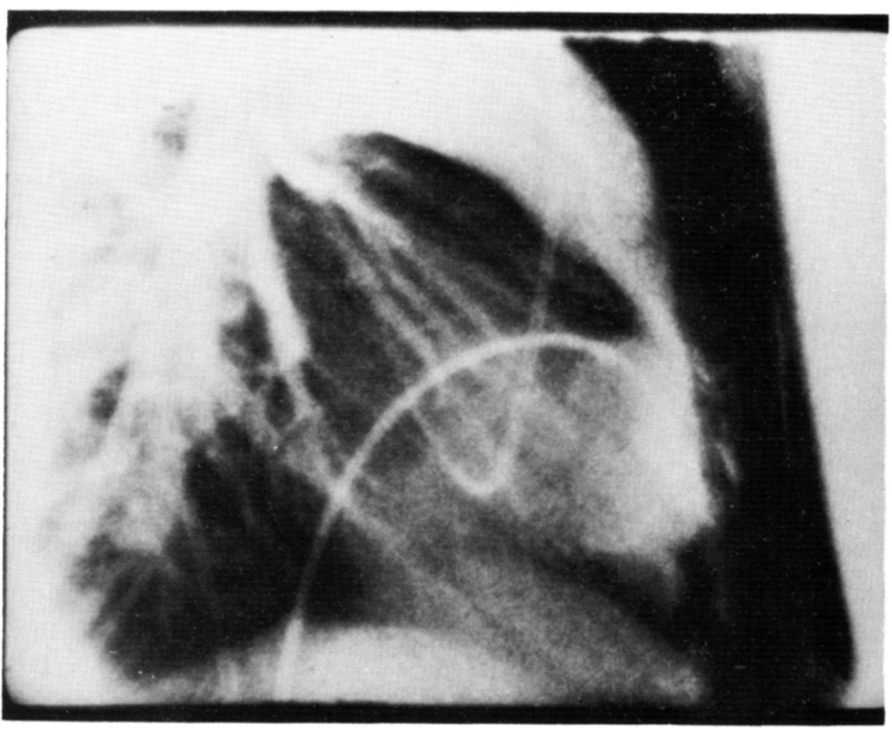

Figure 2 - Right ventricular angiogram in systole (lateral projection). 


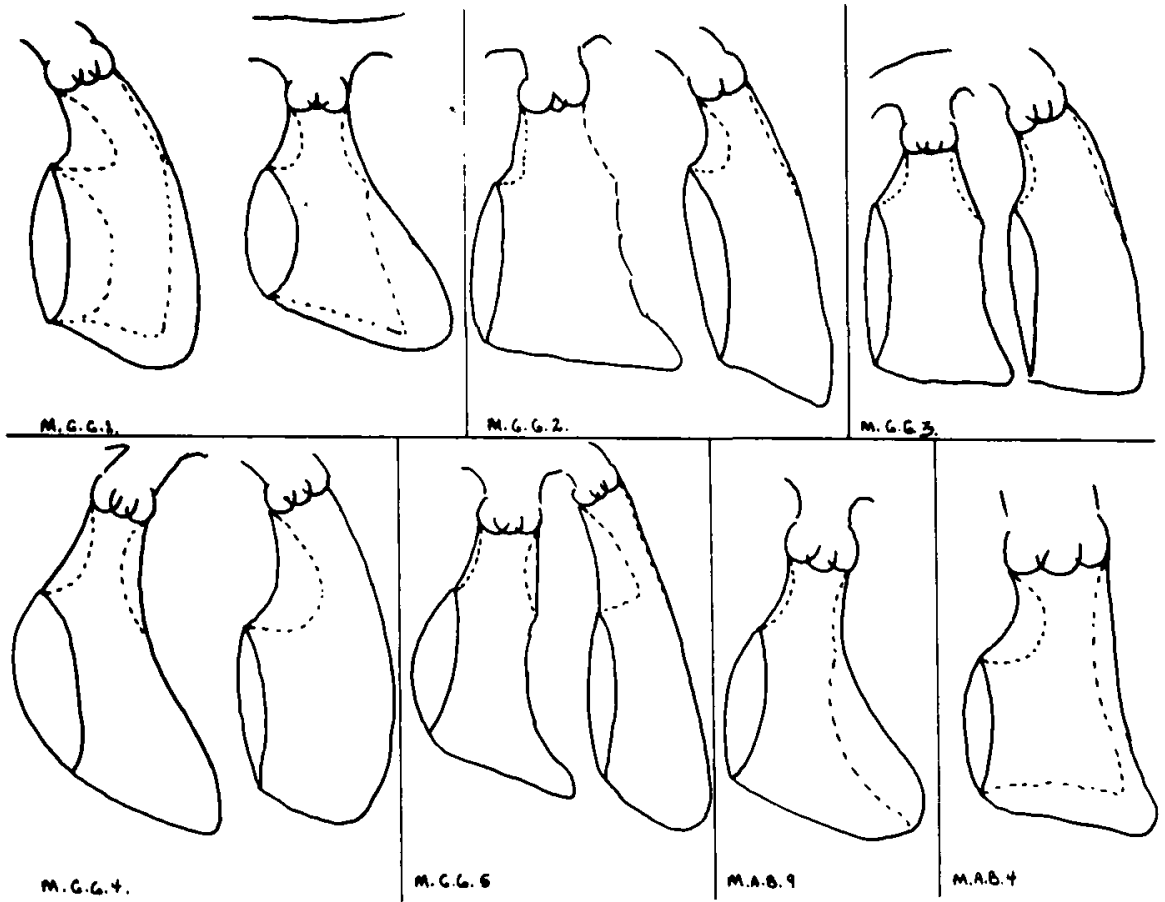

Figure 3 -Right ventricular angiograms. Left, AP view, right lateral view. Solid line: diastole, Hatched line: systole. phology (Figures 6, 7, and 8). In 2 cases, this hypertrophy involved the papillary muscles, particularly the postero-lateral ones. An abnormal position of the anterior mitral valve leaflet secondary to septal hypertrophy as seen in IHSS could not be demonstrated in any case. A discrete posterior mitral valve prolapse was evident in three cases with slight mitral regurgitation in one (Table 1 ). Two cases had a diffusely hypokinetic and hypertrophied left ventricle.

\section{COMMENTS}

The results of this study corroborate previous reports and justify the conclusion that the cardiomyopathy in Friedreich's ataxia is of the hypertrophic type. In the majority of cases ( 10 of 12), the hypertrophy is concentric, and non obstructive (Figures 9 and 10). Less frequently (2 cases), this hypertrophy is accompanied by diffuse hypokinesis and depressed ejection fraction (Figures 11 and 12).

In the 5 cases with a left ventricular angiogram in the lateral plane, no systolic anterior movement of the anterior leaflet of the mitral valve could be visualized. Although a

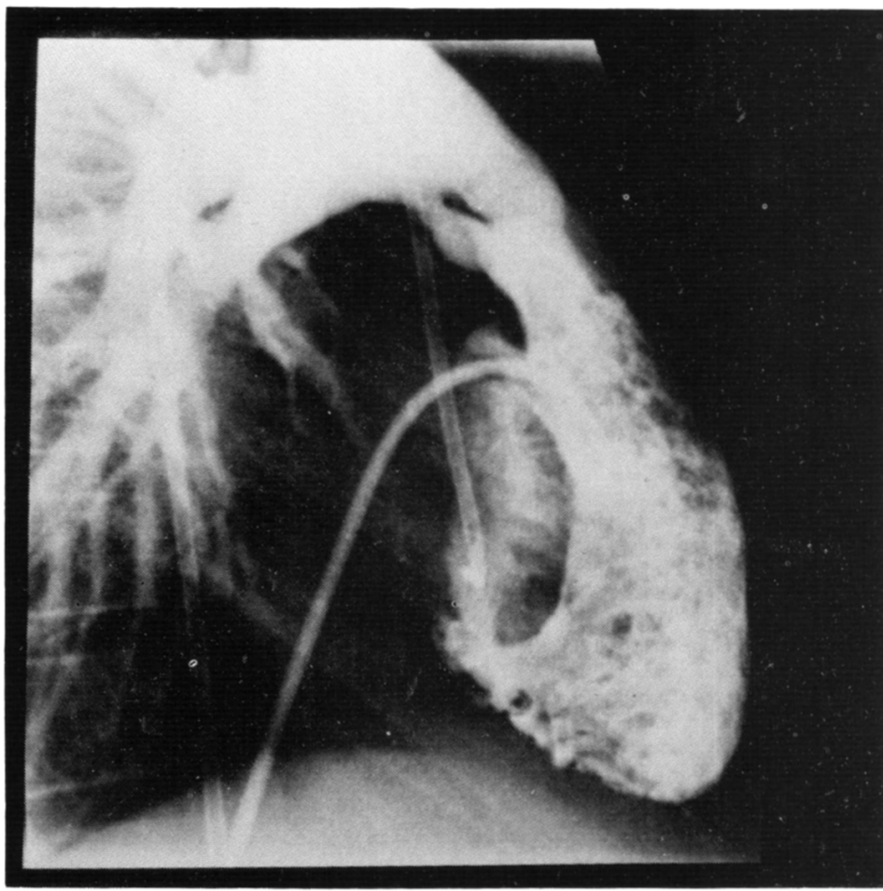

Figure 4 - Right ventricular angiogram in diastole (lateral projection).

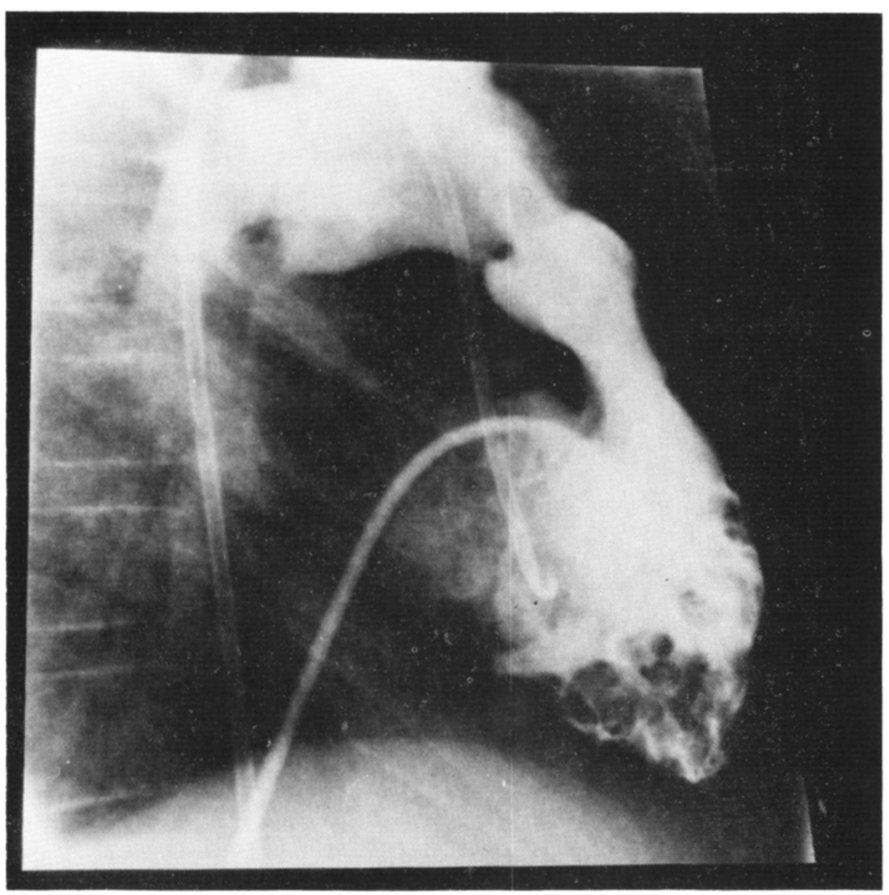

Figure 5 - Right ventricular angiogram in systole (lateral projection). 


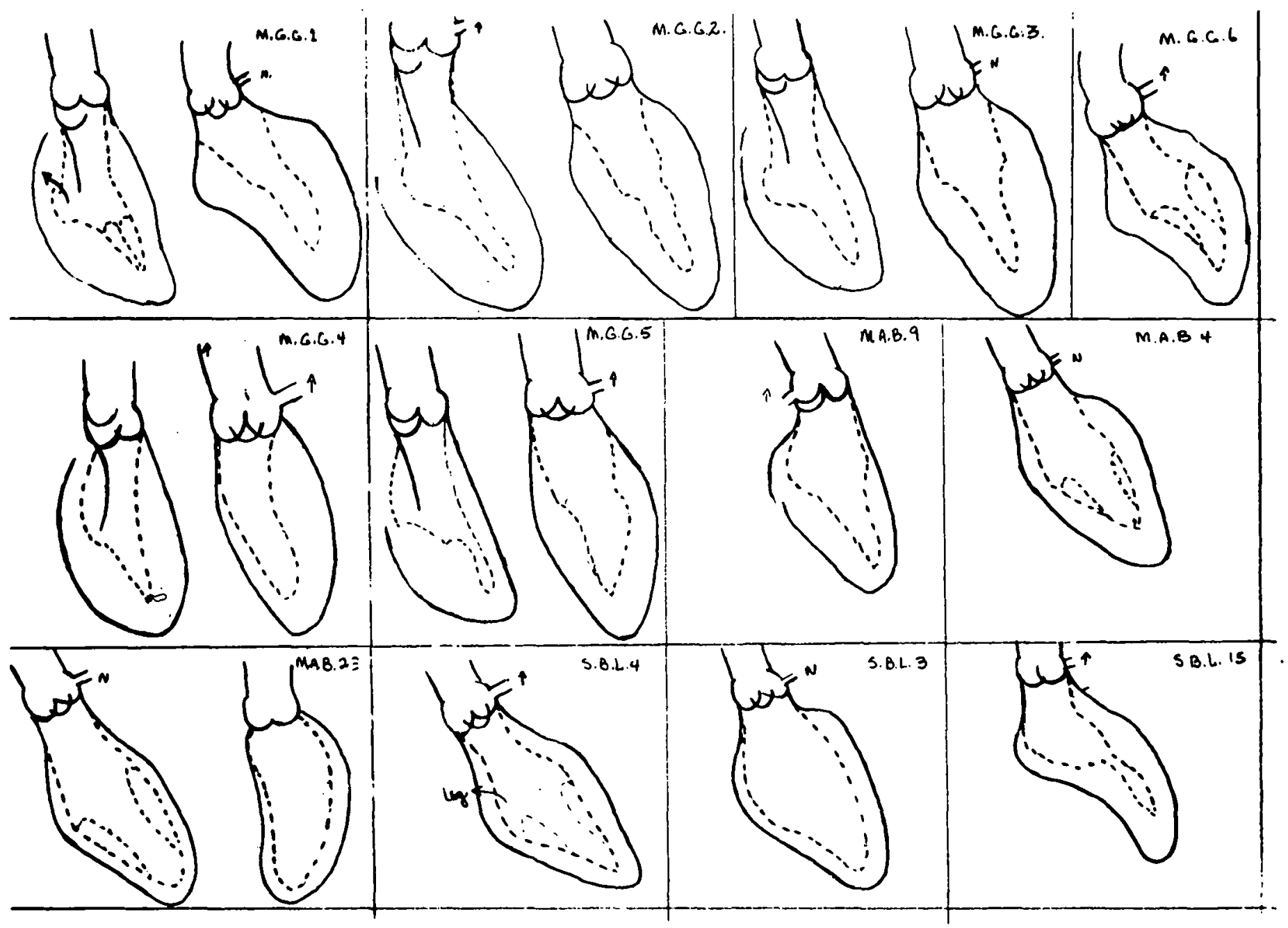

Figure 6- Outline of left ventricular angiograms in diastole (solid line) and systole (hatched lines).

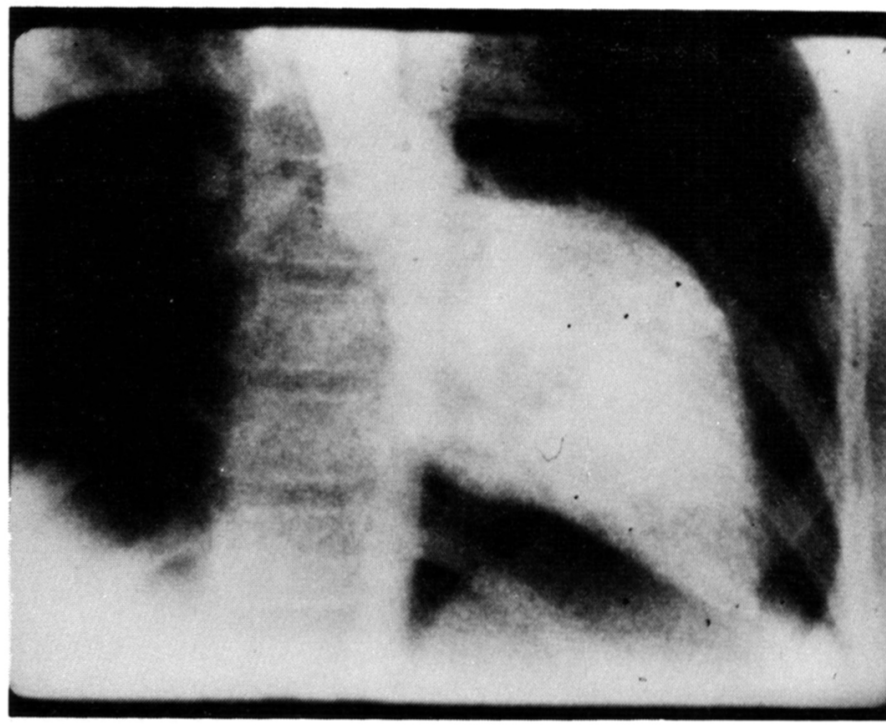

Figure 7 - Left ventricular angiogram in diastole (AP projection).

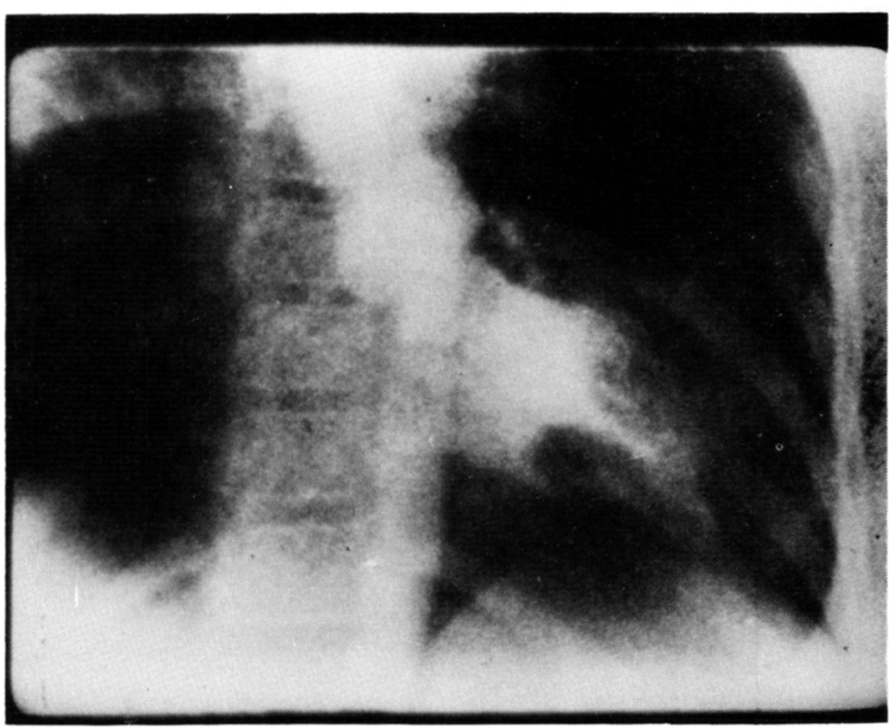

Figure 8- Left ventricular angiogram in systole (AP projection). 


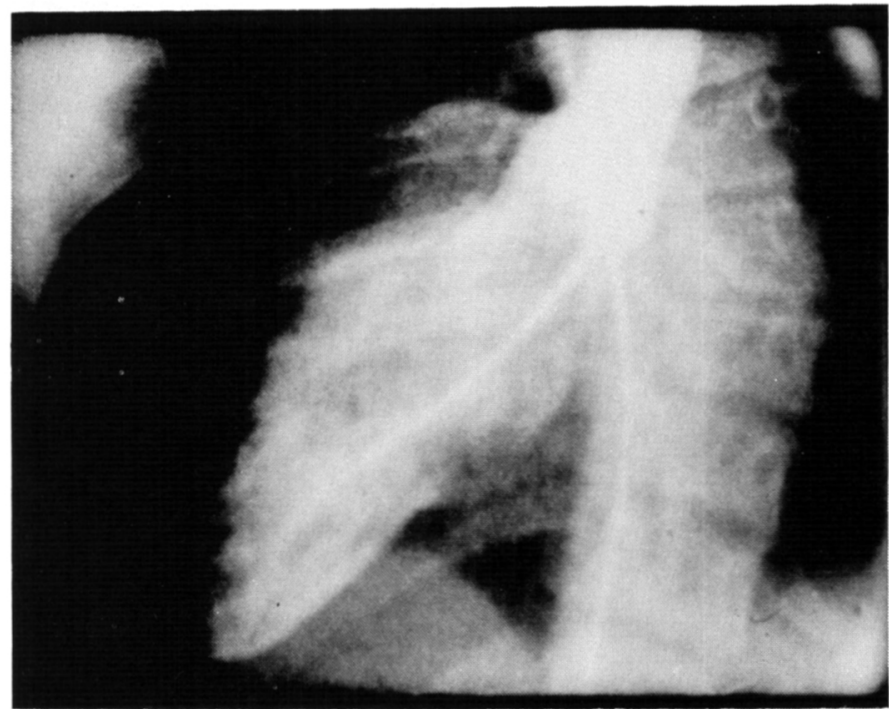

Figure 9- Left ventricular angiogram in diastole (RAO projection).

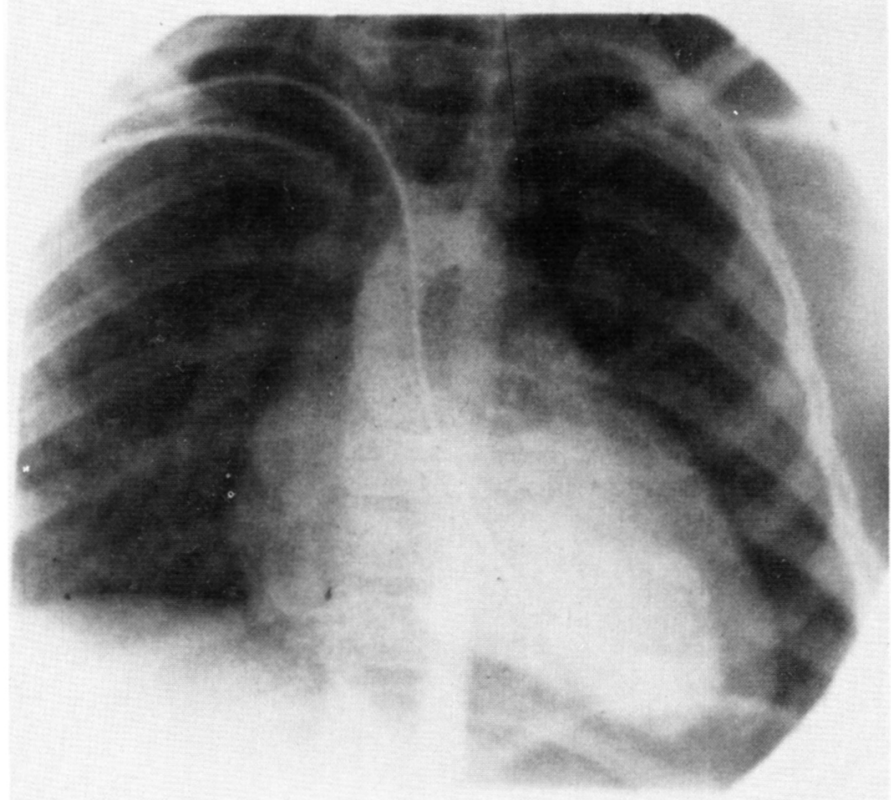

Figure II - Left ventricular angiogram in diastole (AP projection).

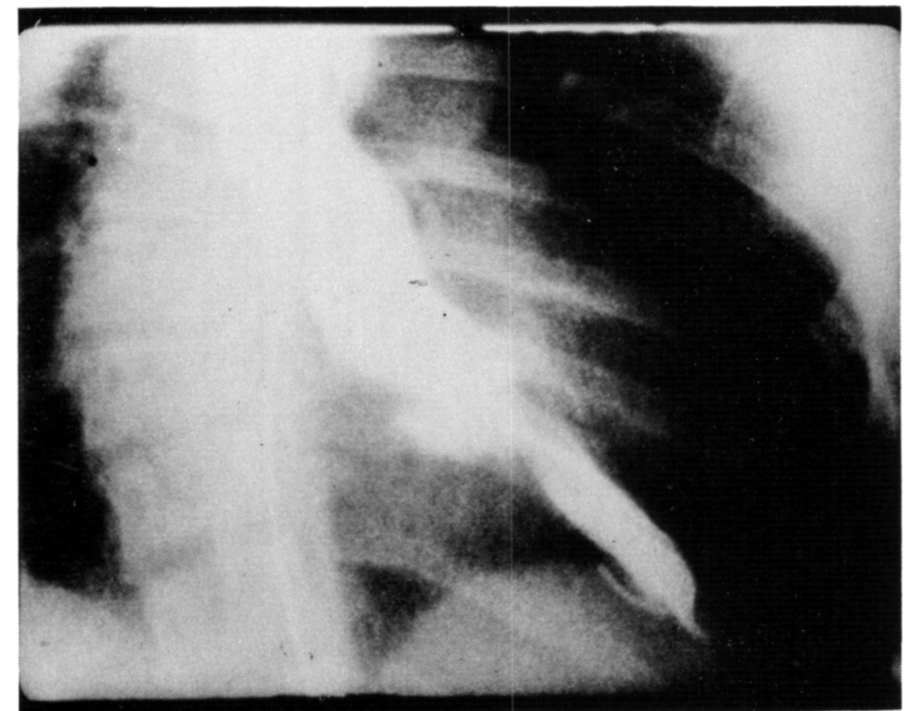

Figure 10 - Left ventricular angiogram in systole (RAO projection).

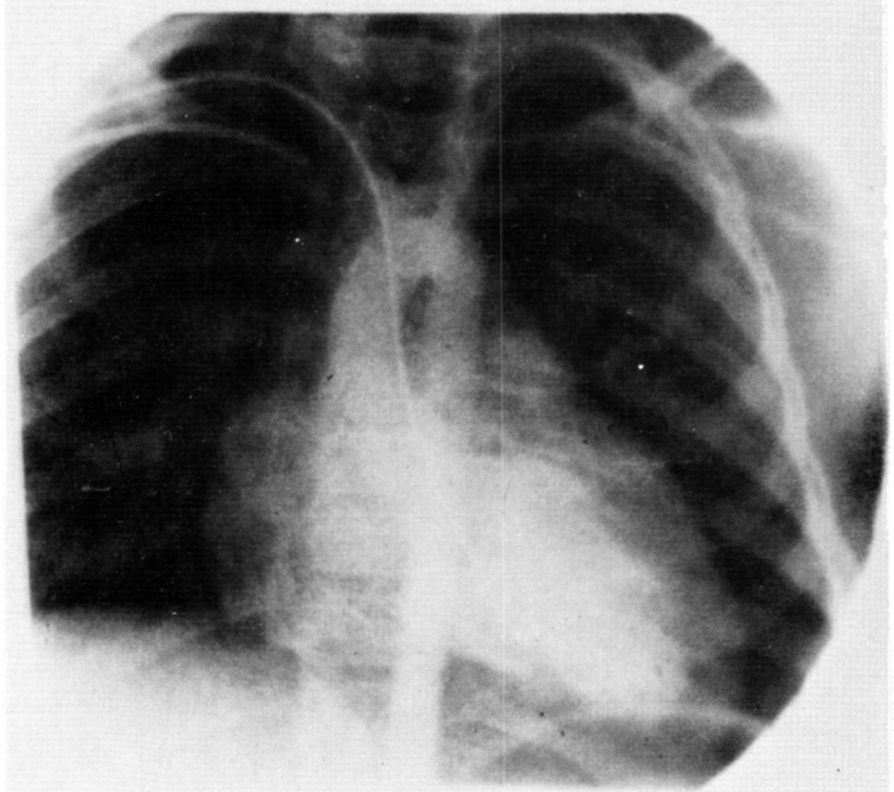

Figure 12 - Left ventricular angiogram in systole (AP projection). dynamic obstruction is infrequent, the experience of others (Ruschhaupt et al., 1972; Thoren, 1964) shows that hemodynamic deterioration and significant obstruction may supervene with progression of the disease.

These findings underline the importance of a thorough clinical and paraclinical evaluation of the cardiovascular status of patients af- fected with Friedreich's ataxia. Although cardiac catheterization may be required in symptomatic patients to adequately assess the severity of the cardiomyopathy and help provide adequate medical supportive therapy, non invasive techniques such as echocardiography, radionucleotide angiography and scanning may be sufficient (Foreman et al., 1973; Bruke, 1971).

\section{ACKNOWLEDGMENTS}

These studies were supported in part by L'Association Canadienne de l'Ataxie de Friedreich and the Medical Research Council of Canada.

\section{REFERENCES}

BOYER, S. H., CHISHOLM, A. W., McKUSICK, V. A. (1962). Cardiac aspects of Friedreich's ataxia. Circulation, $25,493-505$. 
BRUKE, G. (197I). Determination of cardiac output by radioisotope angiography and the image intensifier scintillation camera. J. Nucl. Med., 12, 112-116.

ELIAS. G., GUERIN, R., SPITAELS, S., FOURON, J. C., and DAVIGNON, A. (1972). Sténose musculaire sous-aortique et ataxie de Friedreich. Union Med. Can., 101, 474-478.

FOREMAN, J., VARIN, G., VALTY, J., DAUPTAIN, J., PATRON, G., JOLY, H., and CARLOTTI. J. (1973). Etude hémodynamique des myocardiopathies non obstructives primitives. Archives des maladies du Coeur, 66, 305-322.

GABRIEL, B., PINSARD, N., GERARD, R., and LOUCHET, E. (1974). Association d'une cardiomyopathie et d'une dégénérescence spino-cérébelleuse, (maladie de Friedreich): à propos d'une observation. Pédiatrie, 29, 367-377.

GACH, J. V., ANDRIANGE, M., and FRANCK, G. (1971). Hypertrophic obstructive cardiomyopathy and Friedreich's ataxia. Report of a case and review of literature. Amer. J. Cardiol., 27, 436-44I.
PERNOT, C., TRIDON, P., and HENRY, M. (1973). Coeur et ataxies héréditaires. La Médicine Infantile, 80, 1.

RUSCHHAUPT, D. G., THILENIUS, $O$. G., and CASSELS, D. E. (1972). Friedreich's ataxia associated with idiopathic hypertrophic subaortic stenosis. Amer. Heart. J., 84, 95-102.

THOREN, C. (1962). Cardiomyopathy in Friedreich's ataxia with studies of cardiovascular and respiratory function. Acta Pediat. (Stockholm), 53, suppl., 153-1. 